\title{
Pembangunan Sistem Informasi Pengelolaan Kerja Praktek di Perguruan Tinggi
}

\author{
Eko Budi Setiawan \\ ekobudisetiawan@ymail.com \\ Diterima 7 Mei 2016 \\ Disetujui 18 Juni 2016
}

Program Studi Teknik Informatika, Universitas Komputer Indonesia, Bandung, Indonesia

\begin{abstract}
Abstrak - Implementation Work Practice in Higher Education is a subject that must be done by all students to try to implement the knowledge and skills acquired to society or industry. A large number of students who participated in the Job with limited human resources administration of the College governing its implementation, can cause problems in terms of effectiveness and efficiency of reporting and implementation. With practical work management application is expected to help the parties involved in effecting and improve efficiency in all administrative and reporting processes of practical work process. It also can improve the quality of the presentation of the information provided.
\end{abstract}

Index Terms - Aplikasi, Kerja Praktek, Sistem Informasi, Efektif, Efisien

\section{PENDAHULUAN}

Salah satu proses bisnis akademik dari perguruan tinggi adalah pelaksanaan kerja praktek mahasiwanya. Dalam pengelolaan kerja praktek ini terdapat berbagai proses seperti pencarian data mahasiswa dan dosen, rekap beban membimbing dosen, pembuatan laporanlaporan kerja praktek yang dalam pelaksanaanya dilakukan secara berulang.

Proses - proses di atas tentunya bila dilakukan secara manual akan menyebabkan waktu pengerjaan semakin lama dan kemungkinan terjadi kesalahan semakin besar. Oleh karena itu dibutuhkan dukungan teknologi informasi, dalam hal ini sebuah aplikasi (software) sehingga dalam pelaksanaan proses kerja praktek dapat berjalan lebih efektif dan efisien.

Adapun maksud dari penelitian ini adalah untuk membangun sebuah aplikasi pengelolaan kerja praktek di sebuah perguruan tinggi. Sedangkan yang menjadi tujuan dari penelitian ini yang pertama yaitu untuk meningkatkan efektifitas proses dimana dalam hal ini yang dicapai dengan meminimalisis tingkat kesalahan. Tujuan yang kedua yaitu untuk mengefisiensikan dalam pengelolaan proses kerja praktek dengan mempercepat waktu pengerjaan dalam setiap prosesnya. Kemudian tujuan yang ketiga yaitu untuk meningkatkan kualitas penyajian informasi.

Untuk lingkup pembanguann aplikasi ini meliputi proses pendaftaran kerja praktek, penetapan dosen pembimbing untuk mahasiswa, penyimpanan data transaksi kerja praktek, pengisian nilai kerja praktek, serta pencetakan laporan-laporan mengenai kerja praktek.

\section{LANDASAN TEORI \\ B. Sistem Informasi}

Sistem merupakan kumpulan elemen yang saling berhubungan satu sama lain yang membentuk satu kesatuan dalam usaha mencapai satu tujuan. Menurut penelitian Harianto [1], sistem adalah jaringan kerja dari prosedurprosedur yang saling berhubungan, berkumpul, bersama-sama untuk melakukan suatu kegiatan atau untuk menyelesaikan suatu sasaran tertentu. Suatu sistem pada dasarnya merupakan suatu susunan yang teratur dari kegiatan yang saling berhubungan satu sama lain dan prosedur prosedur yang berkaitan untuk memperudah pelaksanaan kegiatan utama dari suatu organisasi.

Kualitas sistem merupakan kualitas dari sistem yang lebih menekankan kepada kemampuan kinerja hardware dan software dari sistem informasi yang dapat mempengaruhi persepsi pengguna atas kegunaan dan kemudahan penggunaan dari sistem tersebut.

Kualitas sistem merupakan ciri karakteristik kualitas yang diinginkan dari sistem informasi itu sendiri dan kualitas informasi yang diinginkan dari informasi karakteristik produk. Kualitas sistem lebih menekankan kepada kemampuan 
kinerja hardware dan software dari sistem informasi yang dapat mempengaruhi persepsi pengguna atas kegunaan dan kemudahan penggunaan dari sistem tersebut [2].

Indikator yang menentukan kualitas suatu sistem menurut Roger S. Pressman [3] membuat sejumlah faktor-faktor kualitas yang disingkat FURPS (Functionality, Usability, Performance, Reliability dan Supportability).

Informasi menurut Turban et al [4] merupakan data yang telah diorganisir sehingga memberikan arti dan nilai kepada penerimanya. Informasi menurut Jogiyanto [5], merupakan data yang diolah menjadi bentuk yang lebih berguna dan lebih berarti bagi yang menerima dan membutuhkannya. Dengan demikian, dapat disimpulkan bahwa informasi merupakan hasil dari pengolahan data yang memberikan makna atau arti sehingga dapat bermanfaat bagi yang menggunakannya [6].

Menurut Delone Mc Lean dalam penelitian Eko [2] [6] kualitas informasi harus didukung dengan indikator-indikator berikut :

\section{a. Completeness}

Suatu informasi yang dihasilkan oleh sistem informasi dapat di katakan berkualitas jika informasi yang di hasilkannya lengkap. Informasi yang lengkap ini sangat dibutuhkan oleh pengguna dalam pengambilan keputusan. Informasi yang lengkap ini mencakup seluruh informasi yang di butuhkan pengguna.

\section{b. Relevance}

Kualitas informasi dikatakan relevan apabila informasi tersebut mempunyai manfaat bagi penggunanya.

\section{c. Accurate}

Informasi yang dihasilkan oleh sistem informasi harus akurat karena sangat berguna bagi pengguna dalam hal pengambilan keputusan. Informasi yang akurat harus terbebas dari kesalahan-kesalahan. Akurat juga informasi tersebut harus jelas dengan kata lain harus mencerminkan maksud dari informasi yang disediakan oleh sistem informasi.

\section{d. Timeliness}

Informasi yang datang kepada penerima tidak boleh terlambat. Dengan kata lain untuk informasi yang sudah usang maka informasi tersebut sudah tidak memiliki nilai lagi, karena informasi landasan didalam pengmabilan keputusan.

e. Format
Maksudnya agar memudahkan pengguna untuk memahami informasi yang disediakan oleh sistem informasi mencerminkan kulitas informasi yang baik. Jika informasi yang disajikan dalam bentuk yang tepat maka informasi yang dhasilkan dianggap berkualitas, tujuannya untuk memudahkan pengguna.

Pengertian sistem informasi menurut Abdul Kadir [7] yaitu: "Definisi sistem informasi adalah kerangka kerja yang mengkoordinasikan sumber daya manusia dan komputer untuk mengubah masukan menjadi keluaran berupa informasi, guna mencapai sasaran-sasaran perusahaan". Sistem informasi juga merupakan suatu sistem dalam suatu organisasi yang mempertemukan kebutuhan pengolahan transaksi harian yang mendukung fungsi operasi organisasi yang bersifat manajerial dengan kegiatan strategi dari suatu organisasi untuk dapat menyediakan kepada pihak luar tertentu dengan informasi yang diperlukan untuk pengambilan keputusan.

\section{B. Kerja Praktek}

Kerja Praktek atau juga banyak yang megatakan sebagai Kuliah Kerja Nyata (KKN) merupakan suatu mata kuliah wajib yang harus diambil oleh setiap mahasiswa di sebuah Perguruan Tinggi. Mata Kuliah ini biasanya dilakukan di pertengahan studi dari mahasiswa, yaitu diantara semester enam dan semester tujuh bagi mahasiswa strata 1 .

Untuk pelaksanaan program Kerja Praktek di setiap Perguruan Tinggi dipastikan standar prosedurnya berbeda-beda, namun secara umum utnuk tujuan dan pelaksanaannya sama yaitu agar supaya Mahasiswa dapat terjun langsung kepada Masyarakat dan Industri untuk mendapatkan pengalaman serta mengimplementasikan ilmu yang mereka dapatkan di perkuliahan.

Satu bentuk contoh pelaksanaan Kerja Praktek di Universitas XYZ, setiap Mahasiswa akan diarahkan untuk melaksanakan Kerja Praktek ke perusahaan atau instansi pemerintah maupun swasta. Disana mereka dapat melakukan analisis sistem, pembangunan dan pengembangan sistem, analisis desain dan jaringan komputer, serta masih banyak lagi kajian yang bisa dilakukan.

Selain itu, Mahasiswa juga dapat diarahkan pada bentuk Pengabdian Kepada Masyarakat yang dilaksanakan di aparatur desa, koperasi UMKM dalam bentuk melakukan pengembangan sistem existing, pembangunan sistem baru, serta bisa juga dalam bentuk pelatihan dari kompetensi 
yang dimiliki agar dapat diserap oleh kalangan masyarakat.

\section{HASIL DAN PEMBAHASAN}

\section{A. Analisis Spesifikasi Sistem}

Dalam pembangunan aplikasi ini digunakan pendekatan berorientasi objek dimana analisa dan perancangannya akan direpresentasikan dengan menggunakan Unified Modelling Language (UML). Sedangkan untuk bahasa pemrograman yang digunakan menggunakan Java dan MySQL sebagai sistem manajemen basis data.

Aplikasi yang akan dibangun merupakan aplikasi desktop berbasis client server dengan menggunakan metode Java Remote Methode Invocation (RMI) dimana untuk tools development menggunakan NetBeans 7.0.1, Java ver 1.7.0 02 dan Client VM 22.0-b10.

\section{B. Desain Sistem}

Sebelum sistem dibangun kedalam bentuk source code, maka dilakukan terlebih dahulu desain sistem untuk menggambarkan fungsional yang harus ada dalam sistem yang dibangun. Desain sistem tersebut dapat dijelaskan dalam bentuk use case, activity dan class diagram.

\section{B.1. Use Case Diagram}

Use case diagram menggambarkan fungsionalitas yang akan di deliver sesuai dengan sudut pandang pengguna dan interaksi antara aktor dengan sistem. Pada sistem pengelolaan kerja praktek ini, fungsionalitas tersebut diperlihatkan pada gambar 1.

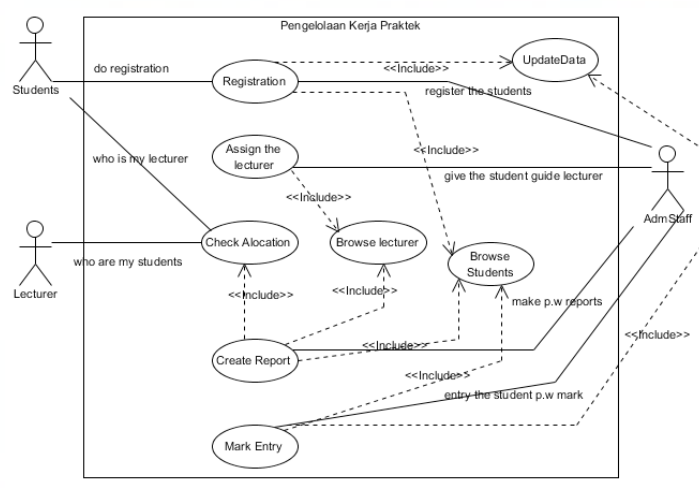

Gambar 1. Use Case Diagram Sistem

Dari gambar 1 tersebut terlihat bahwa ada tiga aktor utama yang akan berinteraksi dengan sistem. Aktor tersebut yaitu Students, Lecturer dan AdmStaff. Ada lima fungsi utama yang ada dalam sistem ini, antara lain :

a. Fungsi Registration : digunakan oleh aktor Students dan AdmStaff untuk melakukan pendaftaran mahasiswa yang akan melaksanakan kerja praktek.

b. Fungsi Assign the lecturer : digunakan oleh aktor AdmStaff untuk mengalokasikan dosen sebagai pembimbing kerja praktek mahasiswa.

c. Fungsi Check Alocation : digunakan oleh aktor Lecturer dan AdmStaff untuk mengecek beban bimbingan kerja praktek dari dosen.

d. Fungsi Create Report : digunakan oleh aktor AdmStaff untuk membuat laporan-laporan seperti daftar peserta KP dan atributnya, daftar pembimbing dan beban bimbingan.

e. Fungsi Mark Entry : digunakan oleh aktor AdmStaff untuk mengisi nilai KP baik dalam bentuk numerik maupun indeks huruf.

Selain fungsi utama di atas, ada tiga fungsi pendukung yang telah teridentifikasi saat ini yaitu:

a. Fungsi Browse Students: fungsi ini digunakan dalam use-case registration, create report dan mark entry untuk meng-inquiry data mahasiswa.

b. Fungsi Browse Lecturer: fungsi ini digunakan dalam use-case set the tutor dan create report untuk meng-inquiry data dosen.

c. Fungsi Update Data: fungsi ini digunakan dalam use-case registration dan mark entry untuk memutakhirkan data kerja praktek mahasiswa, seperti judul kerja praktek dan nilai judul kerja.

\section{B.2. Activity Diagram}

Diagram aktivitas digunakan untuk menjelaskan lebih detail dari aktivitas yang ada pada setiap fungsional dari use case. Berikut ini akan dijelaskan beberapa dari activiy diagram yang ada pada sistem.

\section{B.2.1 Activity Diagram Registration}

Untuk melakukan registrasi, student mendaftarkan dirinya kepada AdmStaff untuk kemudian oleh AdmStaff akan diisi formnya kedalam sistem. Hal ini dikarenakan user hanya diberi akses untuk melihat data setelah registrasi dilaksanakan sebelumnya. Gambar 2 merupakan activity diagram untuk registration. 
ISSN 2085-4579

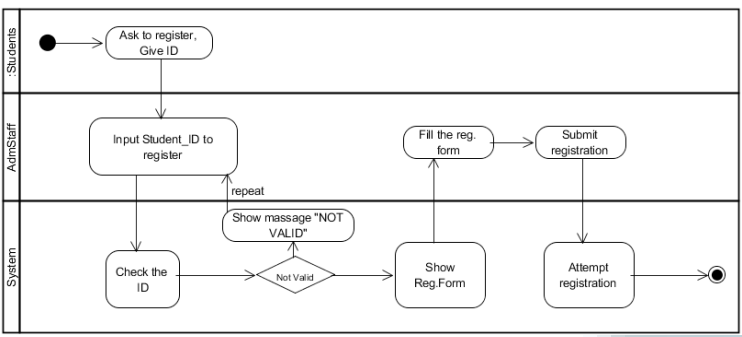

Gambar 2. Activity Diagram Registration

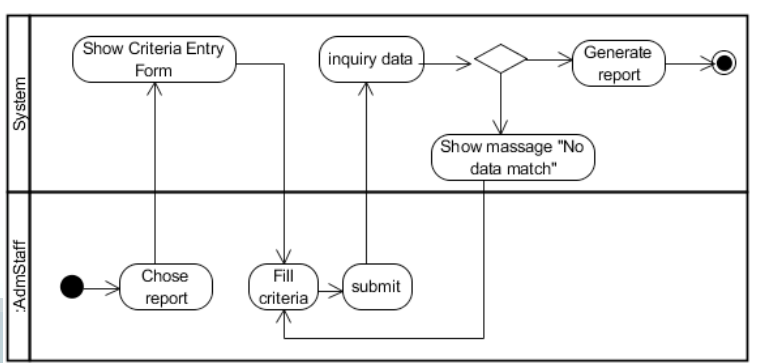

Gambar 5. Activity Diagram Create Report

\section{B.2.5 Activity Diagram Mark Entry}

Aktivitas ini dilakukan oleh AdmStaff untuk menginputkan nilai kerja praktek yang diperoleh dari Lecture. Untuk memudahkan pengisian nilai, disertakan fitur pencarian yang menggunakan nama institusi dan LecturerID. Gambar 6 menunjukan activity diagram mark entry.

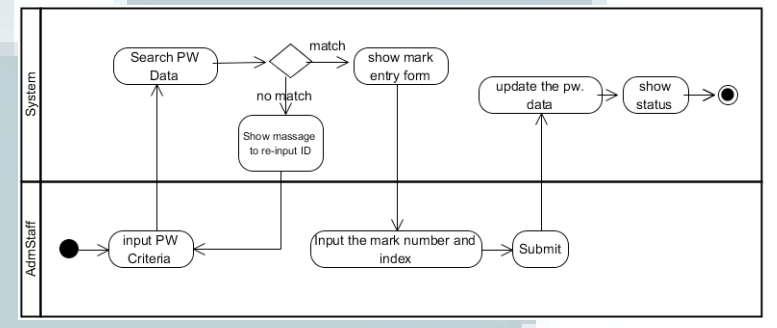

Gambar 6. Activity Diagram Mark Entry

\section{B.3 Class Diagram}

Class Diagram dari sistem yang dibangun dapat dilihat pada gambar 7 berikut ini.

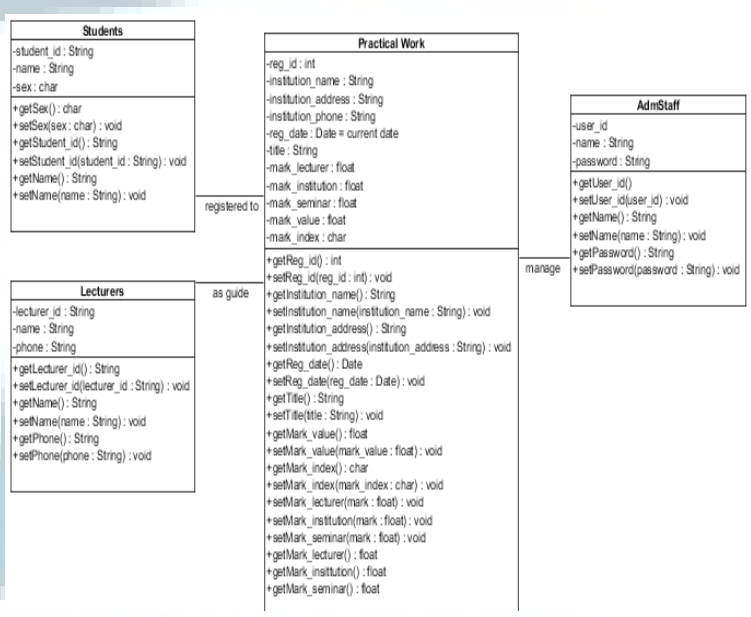

Gambar 7. Class Diagram Sistem

C. Implementasi, Testing dan Analisis

Sewaktu immplementasi penelitian sistem ini dilakukan dengan sistem client server. Semua

\section{ULTIMA InfoSys, Vol. VII, No. 1 | Juni 2016}


fungsional baik dari server side dan client side dapat berjalan dengan baik.

\section{C.1. Implementasi Server Side}

Untuk menjalankan aplikasi ini, langkah awalnya yaitu menjalankan terlebih dahulu aplikasi server side dan database MySQL. Setelah server dijalankan, maka akan menampilkan tampilan seperti pada gambar 8 .

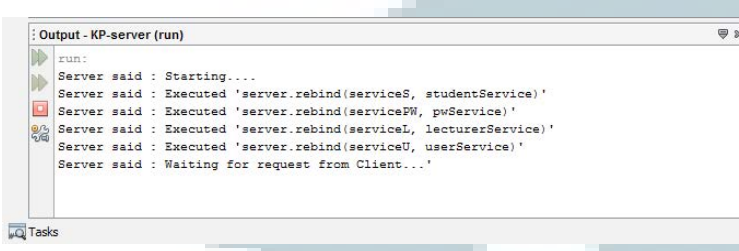

Gambar 8. Log pada saat server berjalan

\section{C.2. Implementasi Form Login}

Setelah server dijalankan, maka langkah selanjutnya yaitu menjalankan client side shingga akan tampil form login seperti pada gambar 9 berikut.

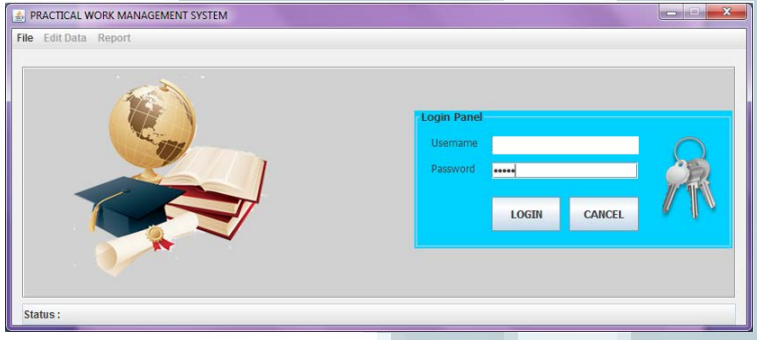

Gambar 9. Tampilan Form Login

\section{C.2. Implementasi Form Utama}

Apabila data login yang diinputkan benar dan sesuai dengan yang ada didalam database, maka menu-menu yang ada dalam aplikasi akan diset enable sesuai dengan kapasitas dari type user login. Apabila type login nya adalah admin, maka semua feature dari aplikasi ini dapat digunakan, tetapi apabila type loginnya adalah sebagai seorang dosen, maka hanya bisa menampilkan menu untuk menampilkan informasi alokasi bimbingan kerja praktek. Tampilan form utama dapat dilihat pada gambar 10 .

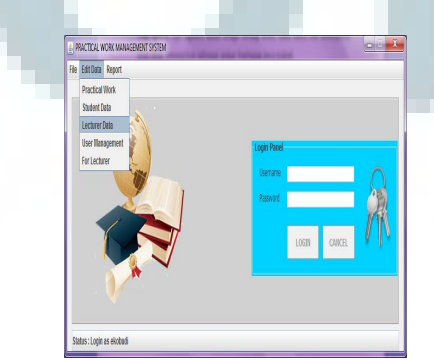

Gambar 10. Tampilan Form Utama

\section{C.3. Implementasi Form Practical Work}

Form Practical Work digunakan untuk melakukan pengelolaan data kerja praktek. Proses yang ada didalam form practical work yaitu :

1. Pencarian data kerja praktek, baik itu pencarian berdasarkan student id, lecturer id atau nama institusi tempat pelaksanaan kerja praktek.

2. Insert data kerja praktek, yaitu mengisi nama, alamat dan nomor telp institusi tempat kerja praktek, tanggal registrasi yang diisi secara otomatis sesuai dengan tanggal insert data, insert judul laporan kerja praktek, mengisi student id yang melakukan kerja praktek, mengeset dosen pembimbing untuk membimbing mahasiswa dalam pelaksanaan kerja praktek, serta memberikan nilai kerja praktek. Nilai kerja praktek merupakan nilai akumulasi dari nilai bimbingan dengan dosen pembimbing, nilai dari perusahaan tempat pelaksanaan kerja praktek, serta nilai pelaksanaan seminar kerja praktek. Untuk bobot penilaian yang digunakan adalah seperti pada tabel 1 berikut :

Tabel 1. Tipe dan Bobot Penilaian

\begin{tabular}{|l|c|}
\hline \multicolumn{1}{|c|}{ Penilaian } & Bobot Nilai \\
\hline Nilai dari Lecturer (bimbingan) & $30 \%$ \\
\hline Nilai dari Institusi & $30 \%$ \\
\hline Nilai Seminar Kerja Praktek & $40 \%$ \\
\hline
\end{tabular}

Apabila tiga tipe penilaian tersebut sudah diisi, maka total kumulatif dan index nilai akan terisi secara otomatis. Untuk range index nilai, menggunakan range nilai seperti pada tabel 2 berikut ini :

Tabel 2. Range Index Nilai

\begin{tabular}{|l|c|}
\hline \multicolumn{1}{|c|}{ Range Nilai } & Index Nilai \\
\hline$>80$ & $\mathrm{~A}$ \\
\hline$>70-80$ & $\mathrm{~B}$ \\
\hline$>61-70$ & $\mathrm{C}$ \\
\hline$>51-60$ & $\mathrm{D}$ \\
\hline$>0-50$ & $\mathrm{E}$ \\
\hline Nilai Default & $\mathrm{T}$ \\
\hline
\end{tabular}

Nilai default $\mathrm{T}$ digunakan untuk mengisi nilai apabila mahasiswa tersebut belum melakukan kerja praktek, hanya sudah melakukan registrasi atau pendaftaran kerja praktek. Ketika student id 
diinputkan, maka setelah menekan tombol enter akan tampil nama mahasiswa yang bersangkutan. Selain itu, untuk mengisi dosen pembimbing kerja praktek dapat juga menggunakan combobox yang sudah terintergrasi dengan database dosen pembimbing.

3. Update data kerja praktek, yaitu mengubah nama, alamat dan nomor telp perusahaan tempat kerja praktek, mengubah judul laporan kerja praktek serta mengubah nilai kerja praktek. Proses update digunakan apabila terdapat data kerja praktek yang perlu dirubah atau di update, seperti adanya kesalahan penulisan tempat perusahaan, ataupun nilai kerja praktek.

4. Delete data kerja praktek, menghapus data kerja praktek.

Adapun tampilan dari hasil implementasi form practical work dapat dilihat pada gambar 11.

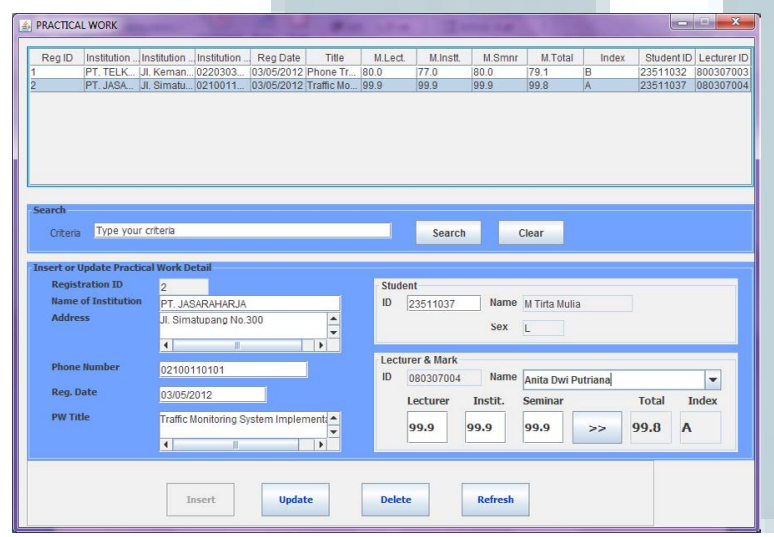

Gambar 11. Tampilan Form Practical Work

\section{C.4. Implementasi Form User Management}

Fitur untuk user management hanya bisa diakses oleh AdmStaff melalui menu utama. Melalui form ini pengguna dapat dibagi kedalam tiga tipe yaitu student, lecturer dan AdmStaff yag masing-masing memiliki hak akses yang berbeda. Tampilannya dapat dilihat pada gambar 12 .

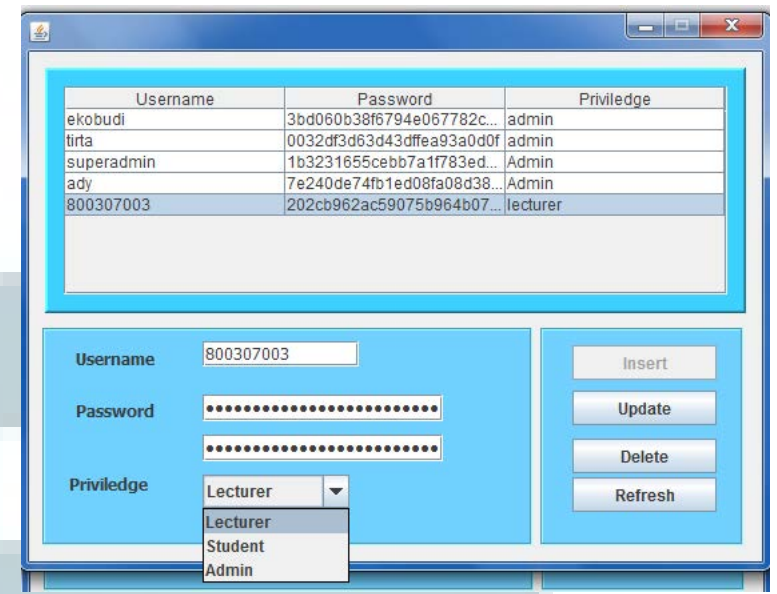

Gambar 12. Tampilan Form User Management

\section{C.5. Implementasi Form For Lecturer}

Form ini dikhususkan agar bisa diakses hanya oleh lecturer saja dengan menggunakan Lecturer_ ID sebagai username. Saat login dari form utama, maka selanjutnya akan diaktifkan menu Report dimana Lecturer bisa memilih form ini saja.

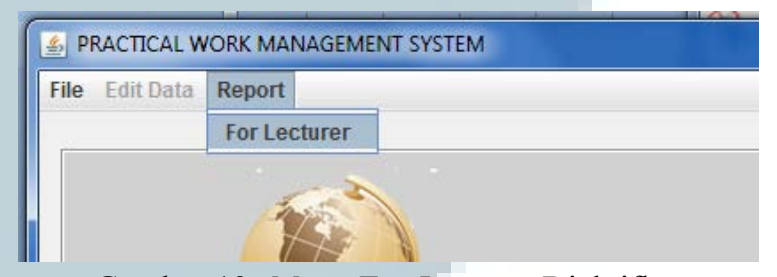

Gambar 13. Mепи For Lecturer Diaktifkan

Form ForLecturer secara otomatis akan menyaring data PracticalWork untuk Lecturer yang sedang login saja. Melalui form ini, Lecturer dapat melihat siapa saja yang dibimbing olehnya dan juga bisa melakukan pencarian berdasarkan judul, nama institusi dan student_ID. Dengan ini Lecturer juga bisa melihat apakah nilai untuk Student tertentu telah diinput atau belum. Tampilannya dapat dilihat pada gambar 14 .

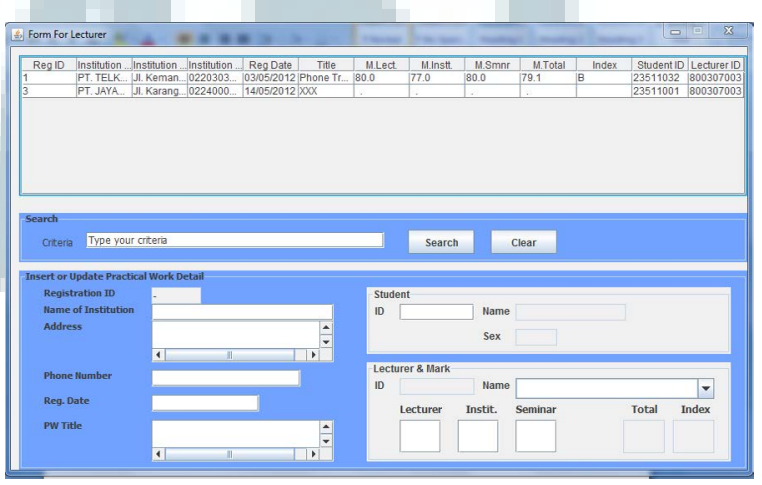

Gambar 14. Form For Lecturer Ditampilkan 
Pada sisi kanan atas, terlihat bahwa Lecturer ID pada datagrid hanya ID "800307003" karena diasumsikan bahwa yang sedang login adalah Lecturer dengan ID tersebut.

\section{C.6. Implementasi Form For Student}

Form ini diperuntukkan bagi Student untuk melihat siapa yang membimbing mereka dan juga nilai akhir apakah telah diinput atau belum setelah mereka seminar. Student hanya memasukkan ID mereka ke textfield yang telah ada dan kemudian data detail Practical Work mereka mulai dari data institusi, alamat, judul lamporan sampai nilai akhir dari kerja praktek akan dicantumkan di layar tersebut. Adapun tampilan dari from student dapat dilihat pada gambar 15 berikut ini :

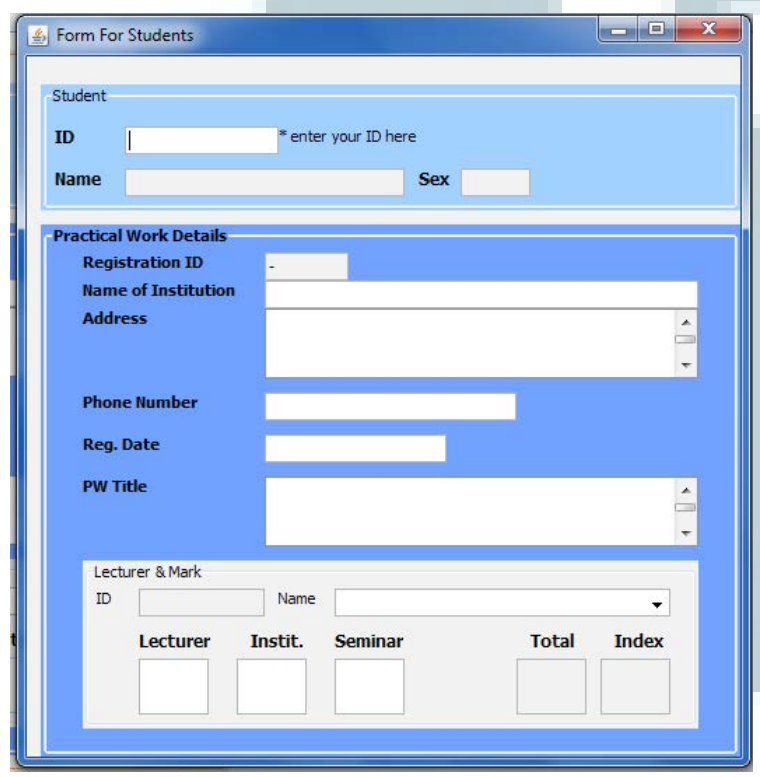

Gambar 15. Form For Student

\section{C.7. Implementasi Error Message}

Aplikasi ini sudah dilengkapi dengan penanganan pesan yang dapat berupa konfirmasi proses atau kesalahan sehingga menampilkan pesan berupa informasi telah terjadi kesalahan sewaktu melakukan inputan. Berikut ini ditampilkan beberapa dari penanganan pesan kesalahan pada sistem.

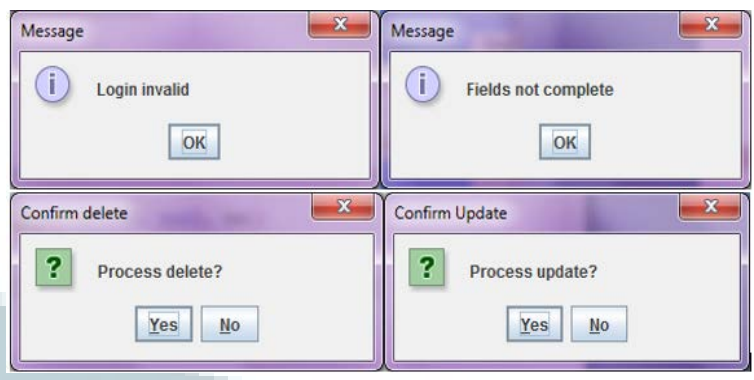

Gambar 16. Tampilan Pesan

Untuk menguji sistem yang dibangun agar supaya tidak terdapat kesalahan dikemudian hari, maka dilakukan pengujian blackblock dengan cara menguji semua fungsionalitas yang ada pada sistem. Berdasarkan hasil pengujian blackbox dari semua fungsional sistem, dapat diambil kesimpulan bahwa pada beberapa proses masih memungkinkan untuk terjadinya kesalahan minor, tetapi secara umum fungsional sudah dapat menghasilkan output yang diharapkan.

Sedangkan untuk mengetahui tingkat penerimaan user terhadap sistem yang dibangun, dilakukan wawancara kepada para stakeholder yang menggunakan sistem di sebuah Perguruan Tinggi yang menjadi tempat penelitian, yaitu pihak sekretariat yang menjadi user sebagai AdmStaff, Dosen terkait yang menjadi user sebagai Lecturer, dan beberapa perwakilan dari mahasiswa yang sedang melaksanakan program kerja praktek.

Hasil yang didapat dari wawancara tersebut, didapatkan bahwa secara umum sistem informasi pengelolaan kerja praktek ini mempunyai kualitas sistem dan informasi yang baik serta sesuai dengan kebutuhan yang diperlukan.

Proses administrasi dan pelaporan kerja praktek sebelumnya memerlukan rata-rata waktu yang cukup lama, karena data dari masing-masing stakeholder tidak tersimpan dalam satu file yang sama. Namun, setelah diimplementasikannya sistem informasi pengelolaan kerja praktek ini, proses pelaporan bisa diselesaikan dalam waktu satu hari saja, karena masing-masing stakeholder dapat dimudahkan dalam setiap kebutuhannya, serta semua informasi yang diperlukan sudah tersedia dalam aplikasi yang dibangun tanpa harus selalu berkoordinasi dengan masingmasing stakeholder.

Sedangkan beberapa saran yang didapatkan dari hasil wawancara tersebut, yang paling diperlukan yaitu agar dapat dikembangkan menjadi multi platform, sehingga aplikasi tersebut 
dapat diakses melalui website dan internet, serta melalui smartphone.

\section{SIMPULAN}

Adapun kesimpulan dan saran yang didapatkan dari hasil penelitian ini yaitu :

\section{A. Kesimpulan}

1. Penelitian ini sudah menghasilkan sistem informasi untuk pengelolaan kerja praktek di perguruan tinggi.

2. Sistem informasi yang dibangun dapat membantu meningkatkan efektifitas dan efisiensi dalam proses pelaporan kerja praktek.

3. Sistem informasi yang dibangun dapat membantu meningkatkan kualitas penyajian informasi yang lebih baik.

\section{B. Saran}

Adapun yang dapat disarankan dari hasil penelitian ini adalah agar untuk selanjutnya dikembangkan menjadi multi platform agar supaya para stakeholder yang dalam hal ini yaitu pihak sekretariat, dosen dan mahasiswa dapat mengaksesnya melalui internet dan smartphone.

\section{DAFTAR PUSTAKA}

[1] Harianto Antonio, Novi Safriadi, 2012. Rancang Bangun Sistem Informasi Administrasi Informatika (SI-ADI). Jurnal ELKHA, Oktober, vol 4 no 2, pp.12-15.

[2] Eko Budi Setiawan, 2015. "Analisis Pengaruh Nilai Teknologi Informasi Terhadap Keunggulan Bersaing Perusahaan”, Jurnal Sains, Teknologi dan Industri, vol 12, no 2, pp.204-211.

[3] Roger S Pressman, Rekayasa Perangkat Lunak: Pendekatan Praktisi, 7th ed. Yogyakarta: Andi, 2012.

[4] Turban, Leidner, McLean, and Wetherbe, Information Technology for Management, 9th ed.: John Wiley \& Sons (Asis) Pte Ltd, 2013.

[5] Jogiyanto, Analisis dan Desain Sistem Informasi : Pendekatan Terstruktur Teori dan Aplikasi Bisnis. Yogyakarta: Andi Offset, 2008.

[6] Eko Budi Setiawan, "Impact of Enterprise Resource Planning (ERP) On Employee Performance," Proceeding ApICT 2013 The 1st International Conference on Applied Information and Communication Technology "Empowering development countries through sustainable ICT", pp. I.15 - 24, October 2013.

[7] Abdul Kadir, Pengenalan Sistem Informasi Edisi Revisi. Yogyakarta: Andi, 2014.

\section{ULTIMA InfoSys, Vol. VII, No. 1 | Juni 2016}

